Article

\title{
Tuning of Hula-Hoop Coordination Geometry in a Dy Dimer
}

\author{
Yan Peng ${ }^{1,2}$, Valeriu Mereacre ${ }^{1}$, Christopher E. Anson ${ }^{1}$ and Annie K. Powell ${ }^{1,2, *}$
}

Received: 18 September 2015; Accepted: 31 December 2015; Published: 8 January 2016

Academic Editors: Stephen Mansell and Steve Liddle

1 Institute of Inorganic Chemistry, Karlsruhe Institute of Technology, Engesserstrasse 15, 76131 Karlsruhe, Germany; Py1688@yahoo.com (Y.P.); valeriu.mereacre@kit.edu (V.M.); christopher.anson@kit.edu (C.E.A.)

2 Institute of Nanotechnology, Karlsruhe Institute of Technology, Postfach 3640, 76021 Karlsruhe, Germany

* Correspondence: annie.powell@kit.edu; Tel.: +49-721-6084-2135; Fax: +49-721-6084-8142

\begin{abstract}
The reaction of $\mathrm{DyCl}_{3}$ with hydrazone Schiff base ligands and sodium acetate in the presence of triethylamine $\left(\mathrm{Et}_{3} \mathrm{~N}\right)$ as base affords two dysprosium dimers: [Dy $\left.2(\mathrm{HL} 1)_{2}(\mathrm{OAc})_{2}(\mathrm{EtOH})(\mathrm{MeOH})\right]$ (1) and $\left[\mathrm{Dy}_{2}(\mathrm{~L} 2)_{2}(\mathrm{OAc})_{2}\left(\mathrm{H}_{2} \mathrm{O}\right)_{2}\right] \cdot 2 \mathrm{MeOH}(\mathbf{2})$. The Dy ${ }^{\mathrm{III}}$ ions in complexes $\mathbf{1}$ and $\mathbf{2}$ are linked by alkoxo bridges, and display "hula hoop" coordination geometries. Consequently, these two compounds show distinct magnetic properties. Complex $\mathbf{1}$ behaves as a field-induced single molecule magnet (SMM), while typical SMM behavior was observed for complex 2 . In addition, comparison of the structural parameters among similar Dy2 SMMs with hula hoop-like geometry reveals the significant role played by coordination geometry and magnetic interaction in modulating the relaxation dynamics of SMMs.
\end{abstract}

Keywords: hydrazone Schiff base; Dy dimer; hula-hoop; single molecule magnets

\section{Introduction}

Recently, considerable attention has been paid to the design of new single molecule magnets (SMMs) involving $4 \mathrm{f}$ metal ions because of their significant magnetic anisotropy arising from the large unquenched orbital angular momentum [1,2]. Several reviews have already been published on SMMs which highlight strategies towards their synthesis and optimisation as well as understanding the factors determining the relaxation dynamics in such molecules [1,3-9]. However, it is still a challenge to understand the structure-property relationships. We know that the interplay between the ligand field effect, the geometry, and the strength of the magnetic interaction between the lanthanide sites will govern the SMM behavior of lanthanide-based SMMs [10]. The design of certain core motifs with different coordination environments (organic ligands, bridged ligands and co-ligands) provide an opportunity to probe the relaxation dynamics of polynuclear complexes, thus enriching the correlation between structure and magnetic properties in a family of dysprosium complexes. Furthermore, we can better understand the structure-property relationship to design Dy ${ }^{\mathrm{III}}$-based compounds with specific magnetic properties. Therefore, dinuclear lanthanide complexes, the simplest molecular units, have become a research hot topic in the field of molecule magnetism, due to their advantages compared with Single-Ion Magnets (SIMs) and the simple structural motif which can be easily controlled. 
Hydrazone-based Schiff base ligands provide one of the most successful ligand types for assembling Dy dinuclear [11,12] or dimer [13-16] systems, exhibiting excellent performance in the construction of molecules with structurally distinct anisotropic centres. Minor changes can have significant implications on the physical characteristics and observed properties of the Dy2 complexes. A suitable bridging ligand is crucial for assembling $\mathrm{Dy}_{2}$ clusters with interesting magnetic properties, due to the difficulty in promoting magnetic interactions between the lanthanide ions through overlap of bridging ligand orbitals with the contracted $4 \mathrm{f}$ orbitals of the Ln ions [1]. As far as we know, no alkoxo-bridged $\mathrm{Dy}_{2}$ complexes with hydrazone-containing Schiff base ligands have been reported to date. With this in mind, we designed two novel ligands, namely 3-hydroxy-naphthalene-2-carboxylic acid (6-hydroxymethyl-pyridin-2-ylmethylene)-hydrazide $\left(\mathrm{H}_{3} \mathrm{~L} 1\right)$ and nicotinic acid (6-hydroxymethyl-pyridin-2-ylmethylene)-hydrazide $\left(\mathrm{H}_{2} \mathrm{~L} 2\right)$, which are obtained by in situ reaction of 6-hydroxymethyl-pyridine-2-carbaldehyde with the corresponding hydrazine (Scheme 1). These ligands provide O, N, N, O-based chelating sites forming coordination pockets which are especially favorable for accommodating lanthanide ions. Here we report two Dy 2 compounds assembled from these two ligands showing so-called "hula hoop" coordination geometries. In this type of geometry, several coordinating atoms of the ligand(s) are arranged in a plane about the central lanthanide ion, which itself lies in this equatorial plane; two further ligands then occupy axial positions above and below the plane. The circle on which the equatorial ligands are situated thus defines a hula-hoop around the axis defined by the lanthanide and the two axial ligands. In contrast to previously published complexes of this type, in which the lanthanides are always bridged by phenoxo and / or hydrazone oxygens, the complexes reported here involve alkoxo-bridges. Furthermore, the relationship between structure and magnetic properties is discussed by comparison with the structural parameters of other Dy 2 SMMs in the literature with mono-hydrazone Schiff base ligands and "hula hoop" coordination geometries.

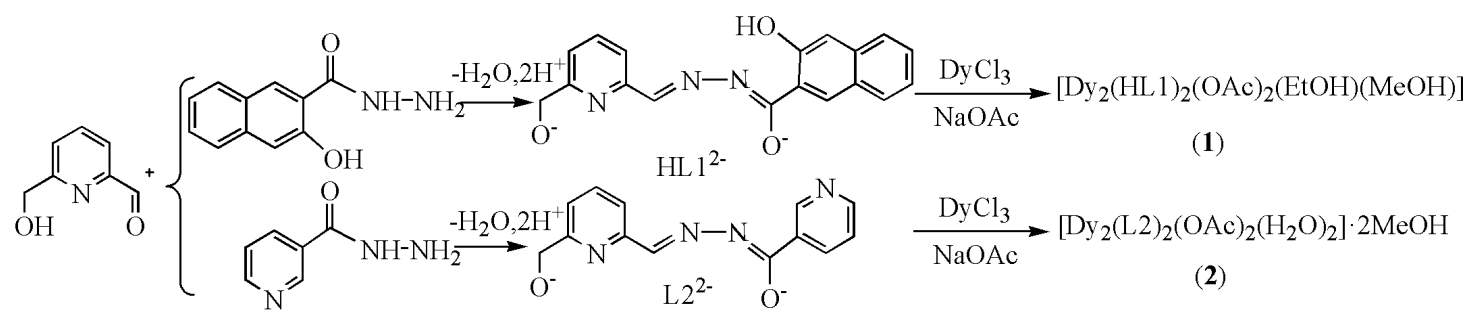

Scheme 1. Synthesis of complexes 1 and 2.

\section{Results and Discussion}

\subsection{Synthesis of compounds 1 and 2}

The two compounds, $\left[\mathrm{Dy}_{2}(\mathrm{HL} 1)_{2}(\mathrm{OAc})_{2}(\mathrm{EtOH})(\mathrm{MeOH})\right](\mathbf{1})$ and $\left[\mathrm{Dy}_{2}(\mathrm{~L} 2)_{2}(\mathrm{OAc})_{2}\left(\mathrm{H}_{2} \mathrm{O}\right)_{2}\right] \cdot 2 \mathrm{MeOH}$ (2), were obtained in good yield from the reaction of 6-hydroxymethyl-pyridine-2-carbaldehyde with either 3-hydroxy-2-naphthoic acid hydrazide or 3-pyridinecarboxylic acid hydrazide, respectively, $\mathrm{DyCl}_{3} \cdot 6 \mathrm{H}_{2} \mathrm{O}$, and $\mathrm{NaOAc} \cdot 3 \mathrm{H}_{2} \mathrm{O}$ in the presence of $\mathrm{Et}_{3} \mathrm{~N}$ as base in the molar ratio 3:3:3:10:10, in $\mathrm{MeOH}$ and $\mathrm{EtOH}$ or $\mathrm{CHCl}_{3}$. Decreasing the amount of the ligands or increasing the amount of metal salt gave no crystals. 


\subsection{Molecular Structures of Compounds $\mathbf{1}$ and $\mathbf{2}$}

The reaction of $\mathrm{DyCl}_{3} \cdot 6 \mathrm{H}_{2} \mathrm{O}$ with either $\mathrm{H}_{2} \mathrm{~L} 1$ or $\mathrm{HL} 2$ in $2: 1 \mathrm{MeOH}$ and $\mathrm{EtOH}$ or $\mathrm{CHCl}_{3}(v / v)$ in the presence of $\mathrm{Et}_{3} \mathrm{~N}$ and $\mathrm{NaOAc} \cdot 3 \mathrm{H}_{2} \mathrm{O}$ leads to the formation of pale yellow crystals of $\mathbf{1}$ or 2 . Crystal data and structure refinement details for $\mathbf{1}$ and $\mathbf{2}$ are summarized in Table S1. Their molecular structures are shown in Figure 1 . Both compounds $\mathbf{1}$ and $\mathbf{2}$ crystallize in the triclinic $\bar{P} \overline{1}$ space group with $Z=1$, and phase purity was confirmed by powder XRD (Figure S1). These two compounds are dimeric Dy ${ }^{\mathrm{II}}$ complexes consisting of eight-coordinated metal centers. The hydrazone Schiff base ligand provides an $\mathrm{N}_{2} \mathrm{O}_{2}$ donor set to each Dy ${ }^{\mathrm{III}}$ with a fifth $\mathrm{O}$ atom provided by the bridging alkoxide function of the ligand from the second Dy $\mathrm{DII}$. This circular environment forms the "hula-hoop" motif first identified in ([I-(dibenzo[18]crown-6) La( $\mu-\mathrm{OH})_{2} \mathrm{La}$ (dibenzo[18]crown-6)I]]) [17,18] for nine coordinated metal ion with six coordination sites in the plan ring and more recently extended to eight coordinated Dy ions with five coordination sites in the plane ring by Tang and co-workers [15]. The coordination sphere is completed by two $\mathrm{O}$ atoms from the bidentate OAc-co-ligand above the plane of the ring and an $\mathrm{O}$ atom from the coordination solvent ( $\mathrm{EtOH} / \mathrm{MeOH}$ for $\mathbf{1}$ and $\mathrm{H}_{2} \mathrm{O}$ for 2 ) below the plane. In the asymmetric unit of $\mathbf{1}$ the coordination solvent is a disordered superposition of $\mathrm{MeOH}$ and $\mathrm{EtOH}$; in the complete molecule there is one of each. The ligation corresponds to a $\eta^{2}: \eta^{1}: \eta^{1}: \eta^{1}: \eta^{0}: \mu_{2}$ coordination mode (Scheme 2), with similar Dy-O bond lengths (2.263(5) and 2.285(4) $\AA$ for $1 ; 2.265(3)$ and 2.274(3) $\AA$ for 2), similar Dy . . Dy distance (3.642(4) for 1 and 3.631(5) A for 2), as well as similar Dy-O-Dy angles (106.42(17) for 1 and 106.23(12) ${ }^{\circ}$ for 2). Additionally, there are intra-molecular hydrogen bonds in complex 1, but no $\pi-\pi$ interaction was found (Figure S3). Whereas for complex 2, there are intra- and inter-molecular hydrogen bonds and short $\pi-\pi(3.7972(4) \AA)$ interactions were found (Figure S3). Furthermore, the closest intermolecular distances between Dy ${ }^{\mathrm{III}}$ ions was found to be $10.65 \AA$ in compound 1, which is much longer than the distance found in compound 2 (7.09 $\AA$ ).

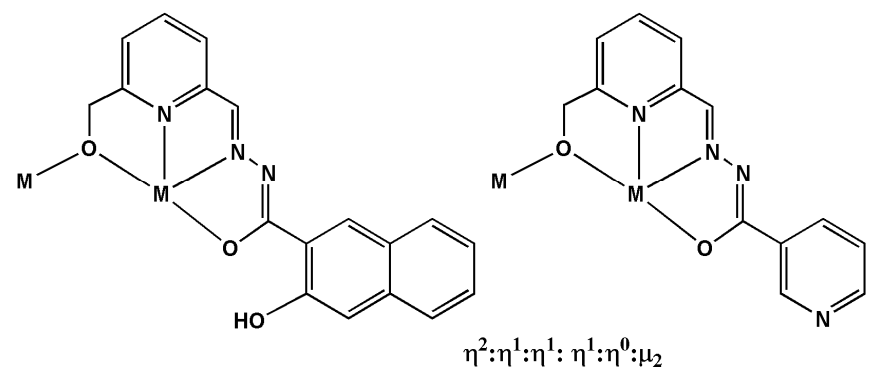

Scheme 2. The coordination modes of the $\mathrm{H}_{3} \mathrm{~L} 1$ and $\mathrm{H}_{2} \mathrm{~L} 2$ in compounds 1 and 2.

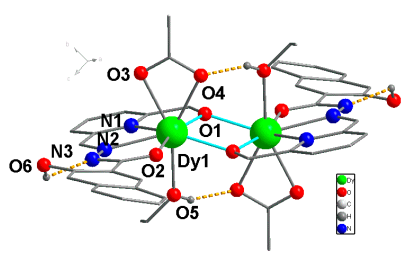

(1)



(4)

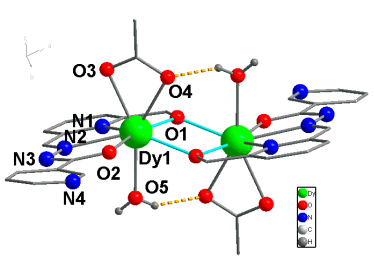

(2)

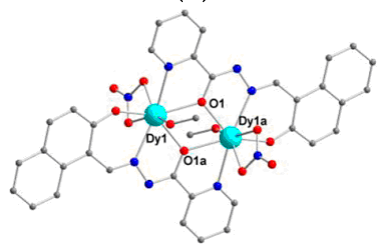

(5)

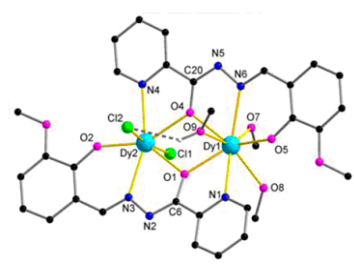

(3)

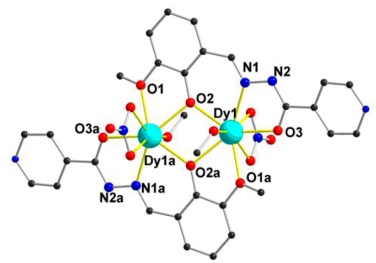

(6)

Figure 1. The molecular structures of compounds 1 and $\mathbf{2}$, and the structures of $\mathrm{Dy}_{2}$ compounds from hydrazine Schiff-base ligands (3, 4, 5 and 6 [11,13-15]). 


\subsection{Magnetic Properties of Compounds $\mathbf{1}$ and 2}

Direct-current (dc) magnetic susceptibilities of $\mathbf{1}$ and $\mathbf{2}$ were measured in an applied magnetic field of $1 \mathrm{kOe}$ between 300 and $1.8 \mathrm{~K}$. The two complexes show almost identical behavior (Figure 2) with observed $\chi T$ values at $300 \mathrm{~K}$ of $28.47 \mathrm{~cm}^{3} \cdot \mathrm{K} \cdot \mathrm{mol}^{-1}$ for 1 and $28.33 \mathrm{~cm}^{3} \cdot \mathrm{K} \cdot \mathrm{mol}^{-1}$ for 2 in good agreement with what is expected for two uncoupled Dy ${ }^{I I I}$ ions $\left(S=5 / 2, L=5,{ }^{6} \mathrm{H}_{15 / 2}, g=4 / 3\right.$, $\left.28.28 \mathrm{~cm}^{3} \cdot \mathrm{K} \cdot \mathrm{mol}^{-1}\right)$. The $\chi T$ value gradually decreases on lowering the temperature to $50 \mathrm{~K}$ and then decreases rapidly to reach $4.84 \mathrm{~cm}^{3} \cdot \mathrm{K} \cdot \mathrm{mol}^{-1}$ for 1 and $7.54 \mathrm{~cm}^{3} \cdot \mathrm{K} \cdot \mathrm{mol}^{-1}$ for 2 at $1.8 \mathrm{~K}$. The decline of $\chi T$ is likely due to a combination of the progressive depopulation of Dy ${ }^{\mathrm{III}}$ excited Stark sublevels $[15,19,20]$ and possibly antiferromagnetic interaction within complexes 1 and 2.

Magnetisation (M) data were collected in the 0-7 T field range at different temperatures. The lack of saturation of magnetisation (Figure S3) suggests the presence of a significant magnetic anisotropy and/or low-lying excited states. The magnetisation increases rapidly at low field and eventually reaches the value of $10.76 \mu_{\mathrm{B}}$ for 1 and $9.84 \mu_{\mathrm{B}}$ for 2 at $7 \mathrm{~T}$ without clear saturation. These values are lower than the expected saturation value of $20 \mu_{\mathrm{B}}(\mathrm{g}=4 / 3)$ for two non-interacting Dy ${ }^{\mathrm{III}}$ ions, most likely due to the crystal-field effect [2].

In order to verify their potential SMM behavior, alternating current (ac) magnetic susceptibility studies were carried out on freshly filtered samples of $\mathbf{1}$ and $\mathbf{2}$. In zero dc field, no out-of-phase signal $\left(\chi^{\prime \prime}\right)$ was observed in 1, indicating the absence of SMM behaviour. Generally, this can be attributed to very fast quantum tunneling of the magnetization (QTM), which is commonly seen in pure lanthanide complexes [21-23]. The QTM may be shortcut by applying a static dc field and thus ac susceptibility measurements were obtained under a static dc field (Figure S4) (0-3 kOe). The optimal field is $2 \mathrm{kOe}$, therefore ac susceptibilities were carried out under this field. From the frequency dependencies of the ac susceptibility (Figure 3 and Figure S5) we can derive the magnetization time in the form of $\tau$ plotted as a function of $1 / \mathrm{T}$ between 4 and $8 \mathrm{~K}$ (Figure 4 ). At lower temperatures, the dynamics of 1 become temperature independent as expected in a pure quantum regime with a value of $1.22 \times 10^{-3} \mathrm{~s}$. Above $5 \mathrm{~K}$, the data obey an Arrhenius law $\tau=\tau_{0} \exp \left(U_{e f f} / k_{B} T\right)$ with an energy barrier of $35.4 \mathrm{~K}$ and pre-exponential factors $\left(\tau_{0}\right)$ of $3.15 \times 10^{-7}$ s. For compound 2 , in zero dc field, the ac susceptibilities measured reveal the presence of slow relaxation of the magnetization, typical of SMM behaviour. The relaxation time shows two distinct regimes stemming from a temperature-independent quantum tunneling regime at low temperatures and a temperature-dependent thermally activated regime at temperatures above $6 \mathrm{~K}$, following an Arrhenius law. The value of energy barrier $\left(U_{e f f}\right)$ and pre-exponential factor $\left(\tau_{0}\right)$ are $38.5 \mathrm{~K}$ and $1.04 \times 10^{-6} \mathrm{~s}$, comparable to those reported for similar Dy2 SMMs [24].

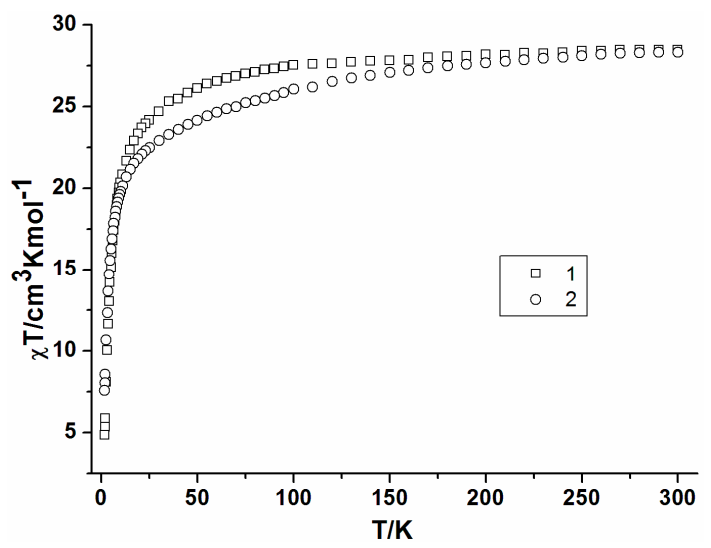

Figure 2. Temperature dependence of the $\chi T$ products at 1000 Oe for $\mathbf{1}$ (square) and $\mathbf{2}$ (circle). 


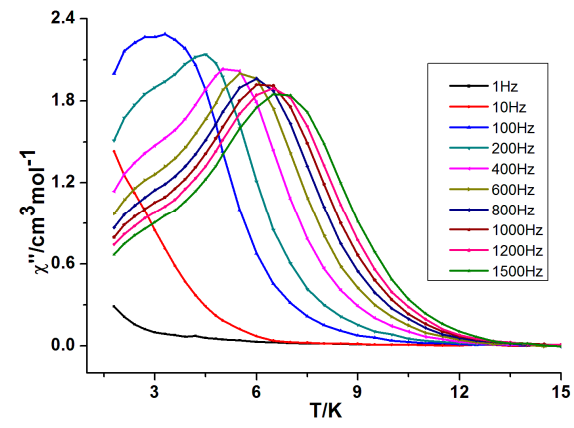

A

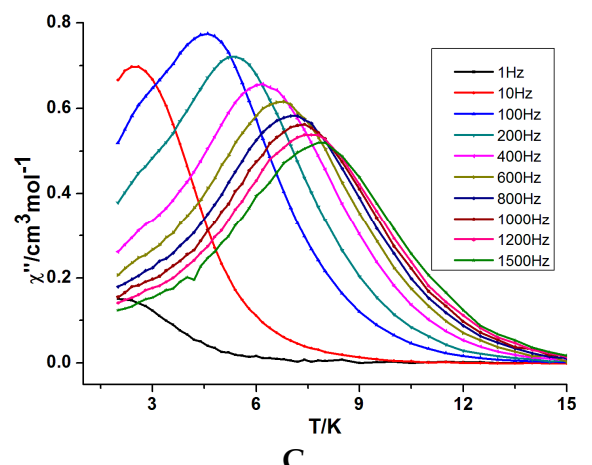

C

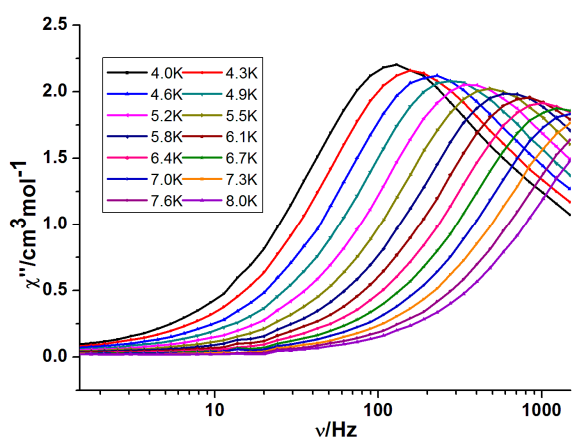

B

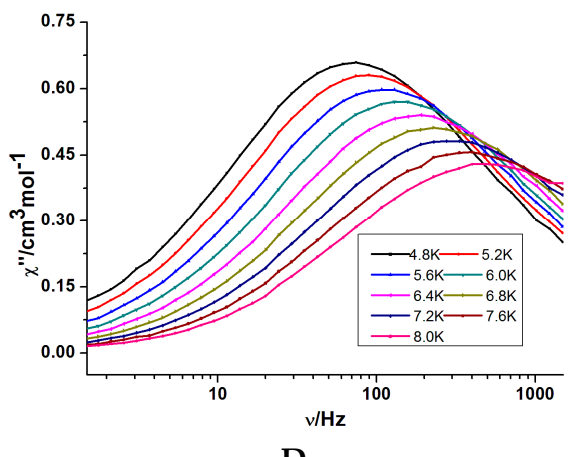

D

Figure 3. Temperature dependence (A) and frequency dependence (B) of the out-of phase ac susceptibility for $\mathbf{1}$ (A,B) under 2000 Oe dc field and Temperature dependence (C) and frequency dependence (D) of the out-of phase ac susceptibility for $\mathbf{2}(\mathbf{C}, \mathbf{D})$ under zero dc field.

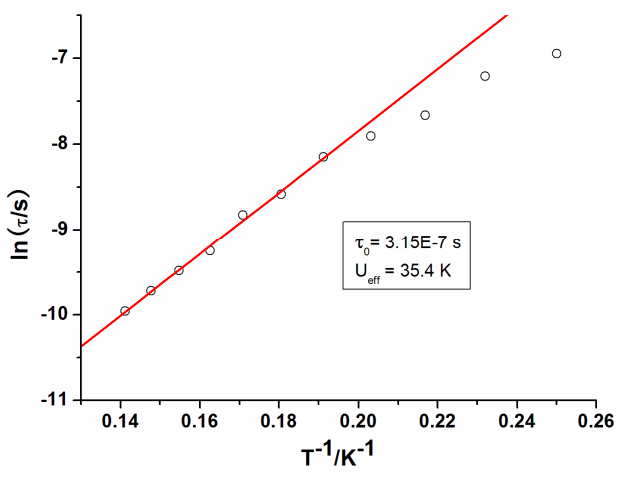

A

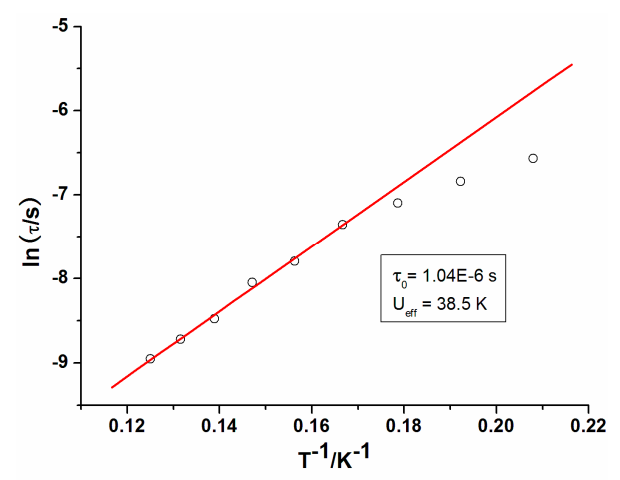

B

Figure 4. Magnetization relaxation time $(\tau)$ vs. $1 / T$ plots for $\mathbf{1}(\mathbf{A})$ under 2000 Oe dc field and 2 (B) under a zero dc field.

The Cole-Cole plots for compounds 1 and 2 from $\chi^{\prime \prime}$ vs $\chi^{\prime}$ at different temperatures are shown in Figure 5. For 1, the shape is asymmetric. A reasonable fit to the generalized Debye model could only be obtained between 5.5 and $7.3 \mathrm{~K}$ with small $\alpha$ values (less than 0.1 , Table S2), suggesting a small distribution of relaxation times in complex $\mathbf{1}$. However, for $\mathbf{2}$, a good fit was obtained according to the Debye model. The $\alpha$ values are below 0.33 (Table S2) which indicates a relatively narrow width of relaxation processes most likely due to a combination of QTM and thermally assisted relaxation pathways [25]. 




A

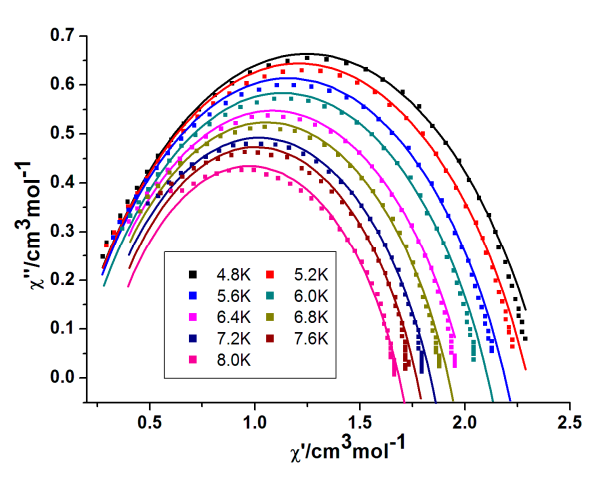

B

Figure 5. Plot of Cole-Cole for $\mathbf{1}$ (A) and 2 (B) at selected temperatures; Lines for fitting.

\subsection{Structure-Property Relationship}

To probe the structure-property relationship in mono-hydrazone Schiff-base ligand based $\mathrm{Dy}_{2}$ SMM systems, some crucial parameters of structure of 1, 2 along with those related compounds [ $\left.\mathrm{Dy}_{2}(\mathrm{ovph})_{2} \mathrm{Cl}_{2}(\mathrm{MeOH})_{3}\right] \cdot \mathrm{MeCN}$ (where $\mathrm{H}_{2} \mathrm{Ovph}=$ pyridine-2-carboxylic acid [(2-hydroxy-3-methoxyphenyl)methylene] hydrazide) 3 [11], [Dy $\left.(\mathrm{ovph})_{2}\left(\mathrm{NO}_{3}\right)_{2}\left(\mathrm{H}_{2} \mathrm{O}\right)_{2}\right] \cdot 2 \mathrm{H}_{2} \mathrm{O} 4$ [15], $\left[\mathrm{Dy}_{2}(\mathrm{~L})_{2}\left(\mathrm{NO}_{3}\right)_{2}(\mathrm{MeOH})_{2}\right] \cdot 4 \mathrm{MeCN}$ (where $\mathrm{H}_{2} \mathrm{~L}=\mathrm{N}^{\prime}$-((2-hydroxy-1-naphthyl)methylene) picolinohydrazide) 5 [14] and $\left[\mathrm{Dy}_{2}(\mathrm{hmi})_{2}\left(\mathrm{NO}_{3}\right)_{2}(\mathrm{MeOH})_{2}\right]$ (where $\mathrm{H}_{2} \mathrm{hmi}=$ 2-hydroxy-3-methoxyphenyl)methylene (isonicotino)hydrazine) 6 [13] are given in Table 1. In terms of other previously reported $\mathrm{Dy}_{2}$ systems [26-28], it is clear that the mono-hydrazone Schiff-base provides a rigidly ligand with different kinds of coordination modes in terms of the available coordination pockets. The tautomeric nature of the arylhydrazone groups makes this system especially favourable for the isolation of such Dy2 SMMs [15]. The "hula-hoop" geometry apparently provides a robust ligand field favouring slow magnetic relaxation of Dy ${ }^{\mathrm{III}}$ ions. In compounds $\mathbf{1}$ and $\mathbf{2}$, each Dy ${ }^{\mathrm{III}}$ ion displays an eight-coordinate $\mathrm{N}_{2} \mathrm{O}_{6}$ coordination environment and links to the other Dy ${ }^{\mathrm{III}}$ via alkoxide $\mu_{2}$-O. As seen in Figure 2, both compounds have similar static magnetic behaviour and are antiferromagnetically coupled.

The dysprosium ions in compounds $3-5$ are bridged by hydrazine- $\mathrm{O}$, while in compound $\mathbf{6}$ they are bridged by phenolate. They show different magnetic behaviour and coupling. Thus it is not possible to predict the nature of the coupling between Dy ions from the Dy-O-Dy angle. Probably, the dominating factors governing the Dy-Dy coupling are a combination of Dy-O length and the local ligand field. For the ac susceptibilities, compound 3 has the highest energy barrier, because of without symmetry, high axiality and strong Ising exchange interaction, which efficiently suppresses quantum tunnelling of the magnetisation. The energy barriers of compound $\mathbf{1}$ and $\mathbf{2}$ are lower, which may be due to the coordinating anions which are different from those in 3 to 6 . A similar behaviour has been previously observed in a Dy dimer system [25]. Also, the axial solvent molecule contributes to this effect in terms of different energy barrier heights [29]. In order to compare the coordination geometries of the Dy ions, these were analysed using the Shape program [30-32]. The results are shown in Table 2, and indicate that the coordination geometries of the Dy ions in 1, 2, 4 and $\mathrm{Dy}_{1}$ in 3 are close to triangular dodecahedral (TDD) with $D_{2 d}$ symmetry. In contrast, the geometries for $\mathrm{Dy}_{2}$ in 3 and the Dy ions in 5, are close to pentagonal bipyramidal (PBPY) with $D_{5 h}$ symmetry, and bicapped trigonal prismatic (BPTR) with $C_{2 v}$ symmetry, respectively. The differences of coordination geometry also contribute to the differences of the energy barrier of above compounds. Last but not least, it is noticeable that, by designing the ligands, suitable modulation of inter- or intramolecular hydrogen bonds or $\pi-\pi$ interactions may have an unexpected effect on magnetic relaxation dynamics $[11,33]$. 
Table 1. Selected parameters of structure of 1, 2 and reported $\mathrm{Dy}_{2}$ compounds based on related ligands (3-6).

\begin{tabular}{|c|c|c|c|c|c|c|}
\hline Compounds & 1 & 2 & $3 *$ & 4 & 5 & 6 \\
\hline Bridging atoms & $\begin{array}{l}\text { Alkoxide } \\
\text { (O) }\end{array}$ & $\begin{array}{l}\text { Alkoxide } \\
(\mathrm{O})\end{array}$ & $\begin{array}{l}\text { Hydrazone } \\
(\mathrm{O})\end{array}$ & $\begin{array}{l}\text { Hydrazone } \\
\text { (O) }\end{array}$ & $\begin{array}{c}\text { Hydrazone } \\
\text { (O) }\end{array}$ & $\begin{array}{l}\text { Phenoxide } \\
\text { (O) }\end{array}$ \\
\hline Geometry $\left(\mathrm{Dy}_{1}\right)$ & hula hoop & hula hoop & $\begin{array}{c}\text { pentagonal } \\
\text { bipyramidal }\end{array}$ & hula hoop & hula hoop & hula hoop \\
\hline Geometry $\left(\mathrm{Dy}_{1^{\prime}} / \mathrm{Dy}_{2}\right)$ & hula hoop & hula hoop & hula hoop & hula hoop & hula hoop & hula hoop \\
\hline Donor atoms in cyclic ring & $\mathrm{N}_{2} \mathrm{O}_{3}$ & $\mathrm{~N}_{2} \mathrm{O}_{3}$ & $\mathrm{~N}_{2} \mathrm{O}_{3}$ & $\mathrm{~N}_{2} \mathrm{O}_{3}$ & $\mathrm{~N}_{2} \mathrm{O}_{3}$ & $\mathrm{NO}_{4}$ \\
\hline $\begin{array}{l}\text { coordination anions } \\
\text { Coordination solvent }\end{array}$ & $\begin{array}{c}\mathrm{Ac}^{-} \\
\mathrm{EtOH}\end{array}$ & $\begin{array}{l}\mathrm{Ac}^{-} \\
\mathrm{H}_{2} \mathrm{O}\end{array}$ & $\begin{array}{l}\mathrm{Cl}^{-} \text {or } \mathrm{MeOH} \\
\mathrm{Cl}^{-} \text {or } \mathrm{MeOH}\end{array}$ & $\begin{array}{c}\mathrm{NO}_{3}^{-} \\
\mathrm{H}_{2} \mathrm{O}\end{array}$ & $\begin{array}{l}\mathrm{NO}_{3}^{-} \\
\mathrm{MeOH}\end{array}$ & $\begin{array}{l}\mathrm{NO}_{3}^{-} \\
\mathrm{MeOH}\end{array}$ \\
\hline $\begin{array}{l}\text { Coordination solvent } \\
\text { Coupling }\end{array}$ & antiferro & $\begin{array}{c}\mathrm{H}_{2} \mathrm{O} \\
\text { antiferro }\end{array}$ & $\begin{array}{l}\mathrm{Cl}^{-} \text {or } \mathrm{MeOH} \\
\text { ferro }\end{array}$ & $\begin{array}{l}\mathrm{H}_{2} \mathrm{O} \\
\text { ferro }\end{array}$ & $\begin{array}{l}\mathrm{MeOH} \\
\text { antiferro }\end{array}$ & $\begin{array}{l}\mathrm{MeOH} \\
\text { ferro }\end{array}$ \\
\hline $\mathrm{d}_{\text {average }}(\AA)$ & 2.384 & 2.384 & 2.370 & 2.355 & 2.387 & \\
\hline Dy-O-Dy $\left(^{\circ}\right)$ & $106.40^{\circ}$ & $105.79^{\circ}$ & $111.67^{\circ}$ & $110.12^{\circ}$ & $114.88^{\circ}$ & $106.41^{\circ}$ \\
\hline Dy-Dy $(\AA)$ & 3.643 & 3.631 & 3.769 & 3.8258 & 3.9225 & \\
\hline Field (Oe) & 2000 & 0 & 0 & 0 & 0 & 0 \\
\hline Ueff $(\mathrm{K})$ & 35.36 & 38.46 & 198,150 & 69 & 41.29 & 56 \\
\hline
\end{tabular}

* Compound 3 is not centrosymmetric but an unsymmetrically coordinated Dy, dinuclear system.

Table 2. Analysis of lanthanide coordination geometry using Shape.

\begin{tabular}{cccccc}
\hline $\mathbf{1}$ & $\mathbf{2}$ & $\mathbf{3}\left(\mathbf{D y}_{\mathbf{1}}\right)$ & $\mathbf{3} \mathbf{( \mathbf { D y } _ { \mathbf { 2 } } )}$ & $\mathbf{4}$ & $\mathbf{5}$ \\
\hline TDD-8 $\left(D_{2 d}\right)$ & TDD-8 $\left(D_{2 d}\right)$ & TDD-8 $\left(D_{2 d}\right)$ & PBPY-7 $\left(D_{5 h}\right)$ & TDD-8 $\left(D_{2 d}\right)$ & BTPR-8 $\left(C_{2 v}\right)$ \\
2.45 & 2.75 & 2.22 & 1.17 & 2.47 & 3.80 \\
\hline \multicolumn{7}{r}{ TDD: Triangular dodecahedron, PBPY: Pentagonal bipyramid, BTPR: Bicapped trigonal prism. }
\end{tabular}

\section{Experimental Section}

\subsection{General Information}

All chemicals and solvents used for synthesis were obtained from commercial sources and used as received without further purification. All reactions were carried out under aerobic conditions. The elemental analyses ( $\mathrm{C}, \mathrm{H}$, and N) were carried out using an Elementar Vario EL analyzer (Elementar Analysensysteme $\mathrm{GmbH}$, Hanau, Germany). Fourier transform IR spectra (4000 to $400 \mathrm{~cm}^{-1}$ ) were measured on a Perkin-Elmer Spectrum GX spectrometer (PerkinElmer LAS GmbH, Rodgau-Jügesheim, Germany) with samples prepared as KBr discs. Powder X-ray diffraction was carried out on a STOE STADI-P diffractometer (STOE \& Cie. GmbH, Darmstadt, Germany), using $\mathrm{Cu}-\mathrm{K} \alpha$ radiation with $\lambda=1.5406 \AA$.

\subsection{The Preparation of $\left[\mathrm{Dy} y_{2}(\mathrm{HL1})_{2}(\mathrm{OAc})_{2}(\mathrm{EtOH})_{2}\right](\mathbf{1})$ and $\left[\mathrm{Dy} \mathrm{y}_{2}(\mathrm{L2})_{2}(\mathrm{OAc})_{2}\left(\mathrm{H}_{2} \mathrm{O}\right)_{2}\right] \cdot 2 \mathrm{MeOH}(\mathbf{2})$}

The ligands were prepared in situ from a solution of 6-hydroxymethyl-pyridine-2-carbaldehyde (21 mg, $0.15 \mathrm{mmol})$ and 3-hydroxy-2-naphthoic acid hydrazide $(26.50 \mathrm{mg}, 0.15 \mathrm{mmol}$ ) or 3-pyridinecarboxylic acid hydrazide $(20 \mathrm{mg}, 0.15 \mathrm{mmol})$ in $5 \mathrm{~mL} \mathrm{MeOH} / \mathrm{EtOH}$ and $10 \mathrm{~mL} \mathrm{CHCl}_{3}$ which was stirred for $30 \mathrm{~min}$ at room temperature. Then $\mathrm{DyCl}_{3} \cdot 6 \mathrm{H}_{2} \mathrm{O}(56.50 \mathrm{mg}, 0.15 \mathrm{mmol})$ was added under stirring. The resulting mixture was stirred for a further $30 \mathrm{~min}$ after $\mathrm{NaOAc} \cdot 3 \mathrm{H}_{2} \mathrm{O}$ $(68 \mathrm{mg}, 0.50 \mathrm{mmol})$ and $\mathrm{EtN}_{3}(0.5 \mathrm{mmol})$ was added. The solution was filtered and the yellow filtrate was left undisturbed to allow for the slow evaporation of the solvent. Yellow needle single crystals, suitable for X-ray diffraction analysis, were formed after one week in $55 \%$ yield (109.6 mg, based on Dy) for $\mathbf{1}\left[\mathrm{Dy}_{2}(\mathrm{HL} 1)_{2}(\mathrm{OAc})_{2}(\mathrm{EtOH})_{2}\right]$ and $65 \%$ yield (111.6 mg, based on Dy) for $\mathbf{2}$ $\left[\mathrm{Dy}_{2}(\mathrm{~L} 2)_{2}(\mathrm{OAc})_{2}\left(\mathrm{H}_{2} \mathrm{O}\right)_{2}\right] \cdot 2 \mathrm{MeOH}$. Anal. Calcd. (Found) \% for $\mathrm{C}_{42} \mathrm{H}_{40} \mathrm{Dy}_{2} \mathrm{~N}_{6} \mathrm{O}_{12}$ 1: C, 44.03 (44.01); H, 3.52 (3.69); N, 7.33 (7.25). Selected IR data $\left(\mathrm{KBr}, \mathrm{cm}^{-1}\right)$ for 1: $3380(\mathrm{w}), 3053(\mathrm{w}), 1601(\mathrm{~s}), 1562(\mathrm{~m})$, 1537 (s), 1508 (m), 1477 (s), 1455 (s), 1441 (m), 1425 (m), 1384 (m), 1341 (s), 1192 (m), 1150 (m), 1095 (w), $1052(w), 1011(w), 927(w), 802(w), 751(m), 652(w), 574(w), 481(w)$. Anal. Calcd. (Found) \% 
for $\mathrm{C}_{30} \mathrm{H}_{30} \mathrm{Dy}_{2} \mathrm{~N}_{8} \mathrm{O}_{10}$ (minus two solvent molecules) 2: C, 36.48 (36.33); H, 3.06 (3.15); $\mathrm{N}, 11.35$ (11.49). Selected IR data (KBr, cm $\left.{ }^{-1}\right)$ for 2: $3402(\mathrm{w}), 3070(\mathrm{w}), 1637(\mathrm{~m}), 1569(\mathrm{~m}), 1537(\mathrm{~s}), 1505$ (m), 1477 (s), 1455 (s), 1441 (m), 1425 (m), 1372 (m), 1341 (s), 1194 (m), 1160 (s), 1095 (m), 1052 (w), 1011 (w), 927 (w), $802(\mathrm{w}), 769(\mathrm{~s}), 652(\mathrm{w}), 576(\mathrm{w}), 481(\mathrm{w})$.

\subsection{X-Ray Crystal Structures}

The crystal structures were determined at $150 \mathrm{~K}$ on a Stoe IPDS II diffractometer with graphite-monochromated Mo-K $\alpha$ radiation. The structures were solved by direct methods and refined by full-matrix least-squares using the SHELXTL [34] program suite.

Crystallographic data (excluding structure factors) for the structures in this paper have been deposited with the Cambridge Crystallographic Data Centre as supplementary publication Nos. CCDC 1442826-1442827. Copies of the data can be obtained, free of charge, on application to CCDC, 12 Union Road, Cambridge CB2 1EZ, UK: https:/ / summary.ccdc.cam.ac.uk/structure-summary-form.

\subsection{Magnetic Measurements}

The magnetic susceptibility measurements were obtained using a Quantum Design SQUID magnetometer MPMS-XL (LOT-Quantum Design, Darmstadt, Germany) in the temperature range 1.8-300 K. Measurements were performed on polycrystalline samples constrained in grease. Magnetization isotherms were collected at 2, 3, $5 \mathrm{~K}$ between 0 and $7 \mathrm{~T}$. Alternating current (ac) susceptibility measurements were performed with an oscillating field of 3 Oe and ac frequencies ranging from 1 to $1500 \mathrm{~Hz}$. The magnetic data were corrected for the sample holder and the diamagnetic contribution.

\section{Conclusions}

In summary, we have utilized 6-hydroxymethyl-pyridine-2-carbaldehyde based mono-hydrazone Schiff-base ligand to assemble two $\mathrm{Dy}_{2}$ compounds bridged by alkoxide $\mathrm{O}$ with an eight-coordinate $\mathrm{N}_{2} \mathrm{O}_{6}$ hula-hoop like coordination environment. The dc magnetic measurements show that two complexes are antiferromagnetically coupled. Remarkably distinct dynamic magnetization was observed. Compound 1 show slow magnetic relaxation with anisotropic barriers of $35.36 \mathrm{~K}$ under $2 \mathrm{kOe}$ dc field, while compound 2 shows slow magnetic relaxation with energy barriers of $38.46 \mathrm{~K}$ under zero dc field. These results provide important evidence that the dynamic behaviour of complexes can be modulated by careful tuning of the structural environments.

Supplementary Materials: Supplementary materials can be accessed at www.mdpi.com/2304-6740/4/1/2/s1.

Acknowledgments: We thank the Deutsche Forschungsgemeinschaft (DFG) for funding via the SFB TR88 “3MET" project.

Author Contributions: The preparation of the manuscript was made by all authors. Yan Peng: Syntheses, IR and Powder X-ray diffraction studies; Valeriu Mereacre: Magnetization studies; Christopher E. Anson: Single crystal X-ray diffraction study; Annie K. Powell: Careful follow-up and improvement of the manuscript, general idea and plan for the publication.

Conflicts of Interest: The authors declare no conflict of interest.

\section{References}

1. Sessoli, R.; Powell, A.K. Strategies towards single molecule magnets based on lanthanide ions. Coord. Chem. Rev. 2009, 253, 2328-2341. [CrossRef]

2. Osa, S.; Kido, T.; Matsumoto, N.; Re, N.; Pochaba, A.; Mrozinski, J. A Tetranuclear 3d-4f single molecule magnet: [Cu $\left.{ }^{\mathrm{II}} \mathrm{LTb}^{\mathrm{III}}(\mathrm{hfac})_{2}\right]_{2}$. J. Am. Chem. Soc. 2003, 126, 420-421. [CrossRef] [PubMed]

3. Sorace, L.; Benelli, C.; Gatteschi, D. Lanthanides in molecular magnetism: Old tools in a new field. Chem. Soc. Rev. 2011, 40, 3092-3104. [CrossRef] [PubMed]

4. Rinehart, J.D.; Long, J.R. Exploiting single-ion anisotropy in the design of f-element single-molecule magnets. Chem. Sci. 2011, 2, 2078-2082. [CrossRef] 
5. Guo, Y.-N.; Xu, G.-F.; Guo, Y.; Tang, J. Relaxation dynamics of dysprosium(III) single molecule magnets. Dalton Trans. 2011, 40, 9953-9963. [CrossRef] [PubMed]

6. Luzon, J.; Sessoli, R. Lanthanides in molecular magnetism: So fascinating, so challenging. Dalton Trans. 2012, 41, 13556-13567. [CrossRef] [PubMed]

7. Palii, A.V.; Tsukerblat, B.; Klokishner, S.; Dunbar, K.R.; Clemente-Juan, J.M.; Coronado, E. Beyond the spin model: Exchange coupling in molecular magnets with unquenched orbital angular momenta. Chem. Soc. Rev. 2011, 40, 3130. [CrossRef] [PubMed]

8. Palii, A.V.; Tsukerblat, B.S.; Clemente-Juan, J.M.; Coronado, E. Isotropic magnetic exchange between anisotropic $\mathrm{Yb}(\mathrm{III})$ ions. Study of $\mathrm{Cs}_{3} \mathrm{Yb}_{2} \mathrm{Cl}_{9}$ and $\mathrm{Cs}_{3} \mathrm{Yb}_{2} \mathrm{Br}_{9}$ crystals. Inorg. Chem. 2005, 44, 3984-3992. [CrossRef] [PubMed]

9. Kostakis, G.E.; Hewitt, I.J.; Ako, A.M.; Mereacre, V.; Powell, A.K. Magnetic coordination clusters and networks: Synthesis and topological description. Philos. Trans. R. Soc. A 2010, 368, 1509-1536. [CrossRef] [PubMed]

10. Long, J.; Habib, F.; Lin, P.-H.; Korobkov, I.; Enright, G.; Ungur, L.; Wernsdorfer, W.; Chibotaru, L.F.; Murugesu, M. Single-molecule magnet behavior for an antiferromagnetically superexchange-coupled dinuclear dysprosium(III) complex. J. Am. Chem. Soc. 2011, 133, 5319-5328. [CrossRef] [PubMed]

11. Guo, Y.-N.; Xu, G.-F.; Wernsdorfer, W.; Ungur, L.; Guo, Y.; Tang, J.K.; Zhang, H.-J.; Chibotaru, L.F.; Powell, A.K. Strong axiality and ising exchange interaction suppress zero-field tunneling of magnetization of an asymmetric Dy 2 single-molecule magnet. J. Am. Chem. Soc. 2011, 133, 11948-11951.

12. Lin, P.-H.; Sun, W.-B.; Yu, M.-F.; Li, G.-M.; Yan, P.-F.; Murugesu, M. An unsymmetrical coordination environment leading to two slow relaxation modes in a $\mathrm{Dy}_{2}$ single-molecule magnet. Chem. Commun. 2011, 47, 10993-10995. [CrossRef] [PubMed]

13. Lin, P.-H.; Burchell, T.J.; Clérac, R.; Murugesu, M. Dinuclear dysprosium(III) single-molecule magnets with a large anisotropic barrier. Angew. Chem. Int. Ed. 2008, 4, 8848-8851. [CrossRef] [PubMed]

14. Zou, L.; Zhao, L.; Chen, P.; Guo, Y.-N.; Guo, Y.; Li, Y.-H.; Tang, J. Phenoxido and alkoxido-bridged dinuclear dysprosium complexes showing single-molecule magnet behaviour. Dalton Trans. 2012, 41, $2966-2971$. [CrossRef] [PubMed]

15. Guo, Y.-N.; Chen, X.-H.; Xue, S.; Tang, J. Modulating magnetic dynamics of three Dy 2 complexes through Keto-Enol tautomerism of the o-vanillin picolinoylhydrazone ligand. Inorg. Chem. 2011, 50, 9705-9713. [CrossRef] [PubMed]

16. Guo, Y.-N.; Chen, X.-H.; Xue, S.; Tang, J. Molecular assembly and magnetic dynamics of two novel Dy 6 and Dy 8 aggregates. Inorg. Chem. 2012, 51, 4035-4042.

17. Runschke, C.; Meyer, G. $\left[\mathrm{La}_{2} \mathrm{I}_{2}(\mathrm{OH})_{2}\right.$ (Dibenzo-18-Krone-6) $\left.{ }_{2}\right] \mathrm{I}\left(\mathrm{I}_{3}\right)$, ein kationischer, dimerer in-cavity-Komplex mit Iodid und Triiodid als Anionen. Z. Anorg. Allg. Chem. 1997, 623, 1493-1495. [CrossRef]

18. Ruiz-Martinez, A.; Casanova, D.; Alvarez, S. Polyhedral structures with an odd number of vertices: Nine-coordinate metal compounds. Chem. Eur. J. 2008, 14, 1291-1303. [CrossRef] [PubMed]

19. Kahn, M.L.; Sutter, J.-P.; Golhen, S.; Guionneau, P.; Ouahab, L.; Kahn, O.; Chasseau, D. Systematic investigations of the nature of the coupling between a $\mathrm{Ln}(\mathrm{III})$ ion $(\mathrm{Ln}=\mathrm{Ce}(\mathrm{III})$ to Dy(III)) and its aminoxyl radical ligands. Structural and magnetic characteristics of a series of $\left\{\operatorname{Ln}(\text { organic radical })_{2}\right\}$ compounds and the related $\left\{\operatorname{Ln}(\text { nitrone })_{2}\right\}$ derivatives. J. Am. Chem. Soc. 2000, 122, 3413-3421.

20. Kahn, M.L.; Ballou, R.; Porcher, P.; Kahn, O.; Sutter, J.-P. Analytical determination of the \{Ln-aminoxyl radical exchange interaction taking into account both the ligand-field effect and the spin-orbit coupling of the lanthanide ion ( $\mathrm{Ln}=\mathrm{Dy}{ }^{\mathrm{III}}$ and $\mathrm{Ho}^{\mathrm{III}}$ ). Chem. Eur. J. 2002, 8, 525-531. [CrossRef]

21. Abbas, G.; Lan, Y.; Kostakis, G.E.; Wernsdorfer, W.; Anson, C.E.; Powell, A.K. Series of isostructural planar lanthanide complexes $\left[\mathrm{Ln}_{4}^{\mathrm{III}}\left(\mu_{3}-\mathrm{OH}\right)_{2}(\mathrm{mdeaH})_{2}(\mathrm{piv})_{8}\right]$ with single molecule magnet behavior for the Dy 4 analogue. Inorg. Chem. 2010, 49, 8067-8072. [CrossRef] [PubMed]

22. Bi, Y.F.; Wang, X.T.; Liao, W.P.; Wang, X.W.; Deng, R.P.; Zhang, H.-J.; Gao, S. Thiacalix[4]arene-supported planar $\mathrm{Ln}_{4}\left(\mathrm{Ln}=\mathrm{Tb}^{\mathrm{III}}\right.$, Dy $\left.{ }^{\mathrm{III}}\right)$ clusters: Toward luminescent and magnetic bifunctional materials. Inorg. Chem. 2009, 48, 11743-11747. [CrossRef] [PubMed]

23. Yan, P.-F.; Lin, P.-H.; Habib, F.; Aharen, T.; Murugesu, M.; Deng, Z.-P.; Li, G.-M.; Sun, W.B. Planar tetranuclear Dy(III) single-molecule magnet and its $\mathrm{Sm}(\mathrm{III}), \mathrm{Gd}(\mathrm{III})$, and $\mathrm{Tb}(\mathrm{III})$ analogues encapsulated by Salen-type and $\beta$-diketonate ligands. Inorg. Chem. 2011, 50, 7059-7065. [CrossRef] [PubMed] 
24. Tuna, F.; Smith, C.A.; Bodensteiner, M.; Ungur, L.; Chibotaru, L.F.; McInnes, E.J.L.; Winpenny, R.E.P.; Collison, D.; Layfield, R.A. A High anisotropy barrier in a sulfur-bridged organodysprosium single-molecule magnet. Angew. Chem. Int. Ed. 2012, 51, 6976-6980. [CrossRef] [PubMed]

25. Habib, F.; Brunet, G.; Vieru, V.; Korobkov, I.; Chibotaru, L.F.; Murugesu, M. Significant enhancement of energy barriers in dinuclear dysprosium single-molecule magnets through electron-withdrawing effects. J. Am. Chem. Soc. 2013, 135, 13242-13245. [CrossRef] [PubMed]

26. Zhang, P.; Guo, Y.-N.; Tang, J. Recent advances in dysprosium-based single molecule magnets: Structural overview and synthetic strategies. Coord. Chem. Rev. 2013, 257, 1728-1763. [CrossRef]

27. Woodruff, D.N.; Winpenny, R.E.P.; Layfield, R.A. Lanthanide single-molecule magnets. Chem. Rev. 2013, 113, 5110-5148. [CrossRef] [PubMed]

28. Habib, F.; Murugesu, M. Lessons learned from dinuclear lanthanide nano-magnets. Chem. Soc. Rev. 2013, 42, 3278-3288. [CrossRef] [PubMed]

29. Martínez-Lillo, J.; Tomsa, A.R.; Li, Y.; Chamoreau, L.M.; Cremades, E.; Ruiz, E.; Barra, A.L.; Proust, A.; Verdaguer, M.; Gouzerh, P. Synthesis, crystal structure and magnetism of new salicylamidoxime-based hexanuclear manganese(III) single-molecule magnets. Dalton Trans. 2012, 41, 13668-13681. [CrossRef] [PubMed]

30. Pinsky, M.; Avnir, D. Continuous symmetry measures, V: The classical polyhedra. Inorg. Chem. 1998, 37, 5575-5582. [CrossRef] [PubMed]

31. Casanova, D.; Cirera, J.; Llunell, M.; Alemany, P.; Avnir, D.; Alvarez, S. Minimal distortion paths in polyhedral rearrangements. J. Am. Chem. Soc. 2004, 126, 1755-1763. [CrossRef] [PubMed]

32. Cirera, J.; Ruiz, E.; Alvarez, S. Generalized interconversion coordinates. Chem. Eur. J. 2006, 12, $3162-3167$. [CrossRef] [PubMed]

33. Bagai, R.; Wernsdorfer, W.; Abboud, K.A.; Christou, G. Exchange-biased dimers of single-molecule magnets in OFF and ON states. J. Am. Chem. Soc. 2007, 129, 12918-12919. [CrossRef] [PubMed]

34. Sheldrick, G.M. Crystal structure refinement with SHELXL. Acta Cryst. C 2015, C71, 3-8. [CrossRef] [PubMed]

(C) 2016 by the authors; licensee MDPI, Basel, Switzerland. This article is an open access article distributed under the terms and conditions of the Creative Commons by Attribution (CC-BY) license (http:/ / creativecommons.org/licenses/by/4.0/). 